\title{
The Role of Transesterification on the Miscibility in Blends of Polycarbonate and Liquid Crystalline Copolyester
}

\author{
Kung-Hwa Wei* and J ia-Chong Ho \\ Institute of Material Science \& Engineering, National Chiao Tung University, \\ Hsinchu, Taiwan 30049, ROC
}

Received October 16, 1996; Revised Manuscript Received J anuary 3, $1997^{\circledR}$

\begin{abstract}
Transesterification mechanisms and rate in blends of polycarbonate (PC) and random liquid crystalline polyester copoly(oxybenzoate-p-terephthalate) at molar ratio 40/60 (P46) were studied through a five-component diad analysis and with ${ }^{13} \mathrm{C}$ and ${ }^{1} \mathrm{H}-{ }^{13} \mathrm{C}$ nuclear magnetic resonance spectroscopy. It was found that the ester-ester interchange in the two polymers took place within 15 min when the blend was annealed at $260{ }^{\circ} \mathrm{C}$ in vacuum. In the annealed blend, the Bisphenol A unit in polycarbonate reacted first with the terephthalate unit and then with the oxybenzoate unit in copoly(oxybenzoate- $p$ terephthalate). As the transesterification in the blend continued for about $1 \mathrm{~h}$, the forming of diad Bisphenol A-oxybenzoate exceeded that of diad Bisphenol A-terephthalate. This large loss (57\%) of the diad oxybenzoate-oxybenzoate caused the disappearance of the liquid crystalline phase in the blend. In sharp contrast to the originally immiscible blend of PC and P46 (two distinctive glass transition temperatures), the large loss of the liquid crystalline diad resulted in complete miscibility in the annealed blend, as evidenced by the appearance of a single glass transition temperature in the differential scanning cal orimetry measurement.
\end{abstract}

\section{Introduction}

Thermotropic liquid crystalline polymers (TLCPs) had attracted a great deal of attention since their arrival. These TLCPS usually contained rigid molecular structures and therefore possessed unique properties such as low melt viscosity and high modulus in the oriented direction in the solid form. The major drawback for these materials in the market place is the high cost of the monomers. From a practical point of view, blending TLCPs with other flexible polymers can lower the blend's viscosity and form organic polymer composites in situ, as described by previous workers. ${ }^{1-5}$ However, liquid crystalline polymer chains are very stiff and of rigid-rod nature. The enthalpy of mixing a rigid-rod polymer with a flexible-chain polymer was mostly positive. The small increase in entropy due to the mixing in these two polymers was not able to compensate for the enthalpy effect. The free energy of mixing is therefore mostly positive. In other words, the miscibility of TLCPs and flexible-chain polymers is not favorable in thermodynamics. Phase separation of TLCP blends occurred where high-stress and -temperature conditions were encountered.6,7 Therefore, the miscibility of TLCP blends is a major obstacle in their applications. Introducing some kind of interaction between TLCPs and a flexible-coil polymer is necessary to improve the miscibility of the two polymers. In this respect, some TLCPs contained unique chemical structures that resulted in reaction with flexible chain polymers. A case in point is the most studied thermotropic copolyesters of oxybenzoate and ethyl ene terephthalate (POB-PET). ${ }^{8}$ A well-known feature for polyesters is that it can have alcoholysis by a hydroxyl end group, acidolysis by an acid end group, and midchain ester-ester interchange (transesterification) with other polymers at high temperatures ${ }^{9,10}$ (generally above 200 $\left.{ }^{\circ} \mathrm{C}\right)$. F or high molecular weight polymers, the probability of having transesterification is much higher than

\footnotetext{
* 886-3-573-1871 (Tel). 886-3-572-4727 (Fax).

${ }^{\otimes}$ Abstract published in AdvanceACS Abstracts, March 1, 1997.
}

that of alcoholysis or acidolysis because of low end group concentrations. Hence, transesterification usually dominated the reaction process in relatively high molecular weight polyesters. Both the solution and melt blends of POB-PET copolyester with poly(butylene terephthalate) (PBT), polycarbonate (PC), and poly(hexamethylene terephthalate) (PHMT) have been studied with differential scanning cal orimetry by various research groups. ${ }^{11-13}$ They have reported that the miscibility of blends of PC/PET, PBT/POB-PET, PC/POB-PET, and $\mathrm{PC} /$ poly(p-oxybenzoate-co-p-phenylene isophthalate) was found to increase with transesterification. ${ }^{11,12,14-16}$ As transesterification in blends continues, new amorphous compatible blends will form. This brings about the fact that the liquid crystalline character in blends is lost, and the purpose of using TLCP blends is destroyed. We are therefore motivated to study the process of transesterification in TLCP blends. We would like to know if there is a point during transesterification where the miscibility of the blends increased while maintaining the liquid crystalline character. Specifically, since two kinds of esters existed in the PET and POB segments of POB-PET copolymers, we wondered if ester-ester interchange takes place randomly or in a preferential manner. Since transesterification between PC and PET has been well studied, we chose a TLCP copolymer of high molar ratio of PET to POB (60/40) for this study. This POB-PET (40/60) copolymer is termed P46. For a theoretical analysis of transesterification in threecomponent copolycondensates, Y amadera ${ }^{17}$ studied the average sequence length and the degree of randomness in blends of poly(ethylene terephthalate) (PET) and poly(ethylene sebacate) (PES). For four-component copolycondensates, Devaux ${ }^{18}$ investigated the sequence length and the randomness in blends of Bisphenol A polycarbonate and poly(butylene terephthalate). Additionally, Kollodge ${ }^{19}$ studied both alcoholysis and transesterification on the phase behavior of blends of PC and lower molecular weight poly(2-ethyl-2-methylpropylene terephthalate) (PEMPT). In this P46/PC blend case, we did a theoretical diad analysis of transesterification of five-component copolycondensates. In order to pinpoint 
the chemical structure changes during transesterification in the P46/PC blend, a model compound study of blends of PC/hydroxybenzoic acid (HBA) and PC/terephthalic acid (TA) at a weight ratio of 80 to 20 has been carried out. This model compound study is similar to that for blends of polyarylate and poly(butylene terephthalate) by previous workers. ${ }^{20}$

\section{Experimental Section}

The copolymer of POB-PET at mole ratio 40/60 (P 46) was synthesized in our Laboratory following the method by Kuhfuss $^{21}$ and was termed P46 in this study. Polycarbonate was purchased from General Electric Co. The trade name of PC is Lexan 121, and its molecular weight is $M_{w}=158900$. The intrinsic viscosity of P46 and PC were 0.53 and $1.15 \mathrm{dL} / \mathrm{g}$, respectively, when they were prepared in mixed solvent of phenol and tetrachloroethane (50/50 by weight). The sol ution blending of PC and P46 was carried out by dissolving both polymers in $25 \mathrm{~mL}$ of a mixed solvent of phenol and tetrachloroethane (50/50). The concentration of the solution containing PC and P46 is $2 \%$ by weight. The weight ratio of PC to P46 in the solution was 40/60. The solution was stirred and heated to $70^{\circ} \mathrm{C}$. After the polymers were completely dissolved and became a one-phase solution for $0.5 \mathrm{~h}$, the solutions were precipitated in a 10 -fold volume of methanol. The blends were then washed five times, each time with $200 \mathrm{~mL}$ methanol. The blends were then dried in a vacuum oven at $100^{\circ} \mathrm{C}$ for 4 days. The thermal gravimetric analysis of the dried blends showed no appreciable weight loss up to $350^{\circ} \mathrm{C}$, indicating a complete removal of the solvent. The 60/40 P46/PC blends were put into a high-temperature vacuum tube at $260{ }^{\circ} \mathrm{C}$ and were annealed for different times. The thermal analysis of the blends was carried out with a DuPont 2910 differential scanning calorimetry (DSC). The samples were heated from 30 to $260^{\circ} \mathrm{C}$, at a heating rate of $20^{\circ} \mathrm{C} / \mathrm{min}$. Then, the samples were cooled quickly to $170{ }^{\circ} \mathrm{C}$ and annealed for $10 \mathrm{~min}$. Subsequently, the samples were quenched to $25^{\circ} \mathrm{C}$. The samples were heated again from 25 to $260^{\circ} \mathrm{C}$ at the same heating rate. The DSC curves of the samples were taken during the second heating. The midpoint of the glass transition was taken as the glass transition temperature $\left(T_{g}\right)$. Without annealing, the DSC curves of the blends did not exhibit separate crystallization (by P46) and glass transition (by PC). Annealing at $170^{\circ} \mathrm{C}$ for $10 \mathrm{~min}$ avoided the problem by allowing the samples to crystallize. Melt-blending of PC/ HBA and PC/TA at a weight ratio of 80/20 was performed in a Brabender mixer at 220 and $300^{\circ} \mathrm{C}$ for $30 \mathrm{~min}$, respectively. HBA can be dissolved in trifluoroacetic acid, while TA cannot. Both PC/HBA and PC/TA reacted blends were dissolved in trifluoroacetic acid and then were filter ed with a filter of 0.45 $\mu \mathrm{m}$ in pore size. The soluble fractions of these solutions were analyzed with nuclear magnetic resonance (NMR).

For nuclear magnetic resonance (NMR) analysis of the 60/ $40 \mathrm{P} 46 / \mathrm{PC}$ blends, $10 \%$ solutions were prepared by dissolving the polymers completely in a mixed solvent of deuterated trifluoroacetic acid and deuterated chlor oform, 15/85 by weight. The NMR spectra were obtained on a Bruker DMX-600 spectrometer. Two-dimensional NMR heter onuclear multiple bond correlation (HMBC) spectra for the blends' solutions were obtained.

\section{Diad Statistical Analysis}

Similar to the analysis in PES/PET by Yamadera ${ }^{17}$ and in PC/PBT by Devaux, ${ }^{18}$ we divided P46 and PC into five components. Monomer units of different chemical structure but of the same functionality were represented by $A_{i}, i=1,2$ (or $B_{j}, j=1,2$ ). We used the notations $(A B)_{1}, B_{1}$, and $A_{1}$ standing for oxybenzoate, terephthalate, and ethylene in $\mathrm{P} 46$, respectively. Bisphenol $A$ and carbonate in PC were noted as $A_{2}$ and $B_{2}$, as listed in Table 1. Before the reaction started, we have $A_{1}(A B)_{1}, A_{1} B_{1},(A B)_{1} B_{1},(A B)_{1}(A B)_{1}$, and $A_{2} B_{2}$. The degree of polymerization is high enough to neglect chain
Table 1. Codes Used in Diads of P46 and PC

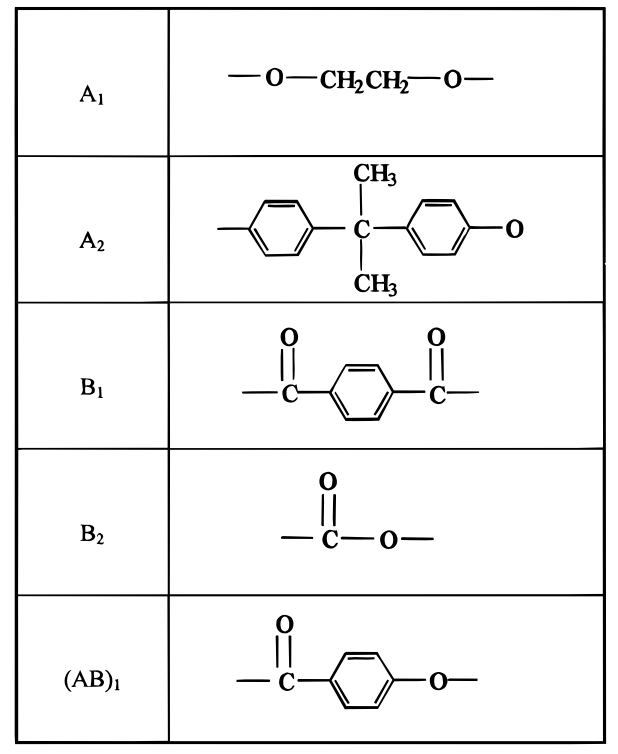

end reaction in this analysis. When the transesterification went on, we had the probability of producing new species $A_{2} B_{1}, A_{2}(A B)_{1}, A_{1} B_{2}$, and $(A B)_{1} B_{2}$.

Before the reaction started, the mole fractions of Bisphenol $A\left(A_{2}\right)$, ethylene $\left(A_{1}\right)$, terephthalate $\left(B_{1}\right)$, carbonate $\left(B_{2}\right)$, and oxybenzoate $\left((A B)_{1}\right)$ were defined by

$$
\begin{aligned}
& F_{A_{i}}=\frac{\left[A_{i}\right]}{\sum_{i=1}^{2}\left[A_{i}\right]+\left[(A B)_{1}\right]} \\
& F_{B_{j}}=\frac{\left[B_{j}\right]}{\sum_{j=1}^{2}\left[B_{j}\right]+\left[(A B)_{1}\right]} \\
& F_{(A B)_{1}}=\frac{\left[(A B)_{1}\right]}{\sum_{i=1}^{2}\left[A_{i}\right]+\left[(A B)_{1}\right]}
\end{aligned}
$$

where brackets stand for the mole concentration of each component in the blend.)

The diad mole fraction of the blend of 60/40 P46/PC is defined by

$\mathrm{F}_{\mathrm{A}_{\mathrm{i}} \mathrm{B}_{\mathrm{j}}}=$

$\frac{\left[A_{i} B_{j}\right]}{\sum_{i, j=1}^{2}\left[A_{i} B_{j}\right]+\sum_{i=1}^{2}\left[A_{i}(A B)_{1}\right]+\sum_{j=1}^{2}\left[(A B)_{1} B_{j}\right]+\left[(A B)_{1}(A B)_{1}\right]}$

or

$$
F_{A_{i} B_{j}}=\frac{\left[A_{i} B_{j}\right]}{\sum_{i=1}^{2}\left[A_{i}\right]+\left[(A B)_{1}\right]}
$$


$\mathrm{F}_{(\mathrm{AB})_{1} \mathrm{~B}_{\mathrm{j}}}=$

$\left[(A B)_{1} B_{j}\right]$

$\overline{\sum_{i, j=1}^{2}\left[A_{i} B_{j}\right]+\sum_{i=1}^{2}\left[A_{i}(A B)_{1}\right]+\sum_{j=1}^{2}\left[(A B)_{1} B_{j}\right]+\left[(A B)_{1}(A B)_{1}\right]}$

or

$$
F_{(A B)_{1} B_{j}}=\frac{\left[(A B)_{1} B_{j}\right]}{\sum_{i=1}^{2}\left[A_{i}\right]+\left[(A B)_{1}\right]}
$$

$\mathrm{F}_{(\mathrm{AB})_{1}(\mathrm{AB})_{1}}=$

$$
\left[(A B)_{1}(A B)_{1}\right]
$$

$\overline{\sum_{i, j=1}^{2}\left[A_{i} B_{j}\right]+\sum_{i=1}^{2}\left[A_{i}(A B)_{1}\right]+\sum_{j=1}^{2}\left[(A B)_{1} B_{j}\right]+\left[(A B)_{1}(A B)_{1}\right]}$

or

$$
F_{(A B)_{1}(A B)_{1}}=\frac{\left[(A B)_{1}(A B)_{1}\right]}{\sum_{i=1}^{2}\left[A_{i}\right]+\left[(A B)_{1}\right]}
$$

The probability of finding an $A_{i}$ group followed by $a B_{j}$ unit, $\mathrm{PA}_{\mathrm{i}} \mathrm{B}_{\mathrm{j}}$, would be

$$
P_{A_{i} B_{j}}=\frac{\left[A_{i} B_{j}\right]}{\sum_{j=1}^{2}\left[A_{i} B_{j}\right]+\left[A_{i}(A B)_{1}\right]}=\frac{\left[A_{i} B_{j}\right]}{\left[A_{i}\right]}
$$

$P_{A_{i} B_{j}} \neq P_{B_{j} A_{i}}(i \neq j)$ (except an equimolar blend)

$$
\begin{gathered}
P_{A_{i}(A B)_{1}}=\frac{\left[A_{i}(A B)_{1}\right]}{\sum_{j=1}^{2}\left[A_{i} B_{j}\right]+\left[A_{i}(A B)_{1}\right]}=\frac{\left[A_{i}(A B)_{1}\right]}{\left[A_{i}\right]}(10) \\
P_{(A B)_{1} B_{j}}=\frac{\left[(A B)_{1} B_{j}\right]}{\sum_{j=1}^{2}\left[(A B)_{1} B_{j}\right]+\left[(A B)_{1}(A B)_{1}\right]}=\frac{\left[(A B)_{1} B_{j}\right]}{\left[(A B)_{1}\right]} \\
P_{(A B)_{1}(A B)_{1}}=\frac{\left[(A B)_{1}(A B)_{1}\right]}{\sum_{j=1}^{2}\left[(A B)_{1} B_{j}\right]+\left[(A B)_{1}(A B)_{1}\right]} \\
\frac{\left[(A B)_{1}(A B)_{1}\right]}{\left[(A B)_{1}\right]}
\end{gathered}
$$

From the above equation we obtained the following relation:

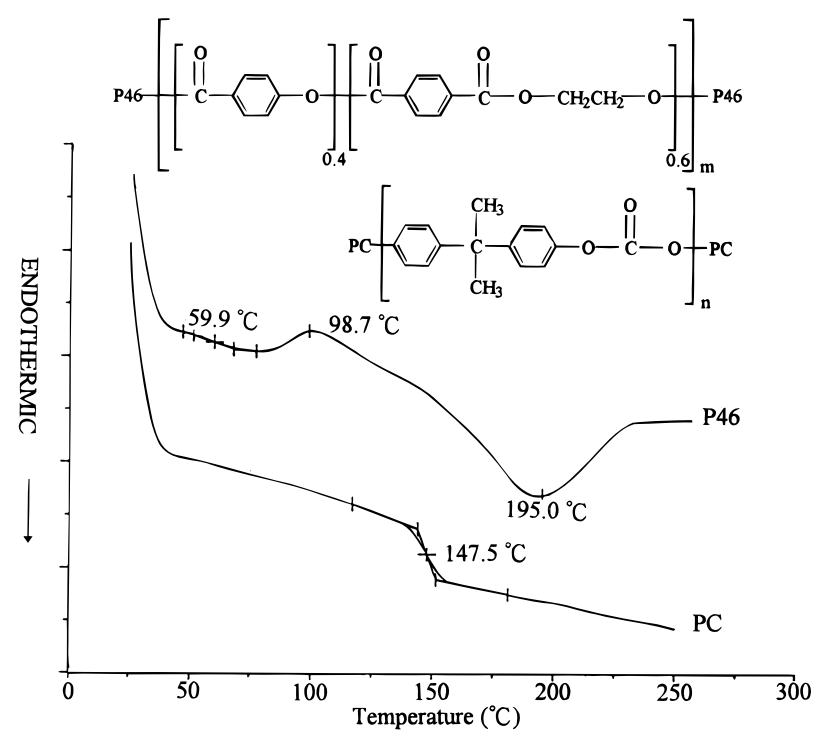

Figure 1. Differential scanning curves and chemical structures of P46 and PC.

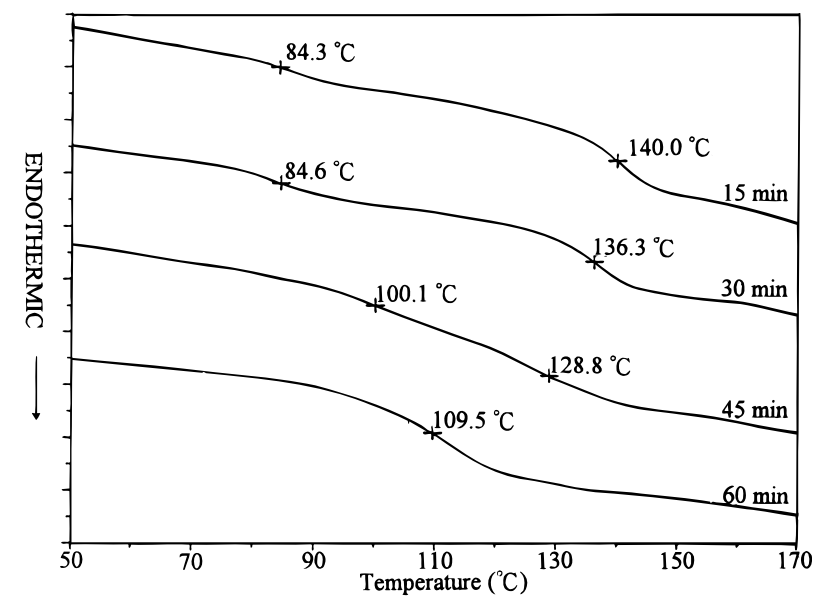

Figure 2. Partial differential scanning curves of the $60 / 40$ $\mathrm{P} 46 / \mathrm{PC}$ solution blend annealed at $260^{\circ} \mathrm{C}$ for different times.

$$
\begin{gathered}
F_{A_{i} B_{j}}=F_{A_{i}} P_{A_{i} B_{j}}=F_{B_{j}} P_{B_{j} A_{i}} \\
F_{A_{i}(A B)_{1}}=F_{A_{i}} P_{A_{i}(A B)_{1}}=F_{(A B)_{1}} P_{(A B)_{1} A_{i}} \\
F_{(A B)_{1} B_{j}}=F_{(A B)_{1}} P_{(A B)_{1} B_{j}}=F_{B_{j}} P_{B_{j}(A B)_{1}} \\
F_{(A B)_{1}(A B)_{1}}=F_{(A B)_{1}} P_{(A B)_{1}(A B)_{1}}
\end{gathered}
$$

The integrals under the resonance peak of ${ }^{13} \mathrm{C} N M R$ spectra of 60/40 P46/PC are proportional to the copolycondensate diad probabilities.

\section{Results and Discussion}

The DSC curves and chemical structure of P46 and $P C$ are shown in Figure 1 . The glass transition temperatures $\left(\mathrm{T}_{\mathrm{g}}\right.$ 's) of $\mathrm{PC}$ and $\mathrm{P} 46$ are 147.5 and $59.9^{\circ} \mathrm{C}$, respectively. The crystallization temperature $\left(T_{c}\right)$ for $\mathrm{P} 46$ and is $98.7^{\circ} \mathrm{C}$. The broad endothermic peak is the melting point of crystalline PET. In this study, the $\mathrm{T}_{\mathrm{g}}$ of P46 belonged to the PET-rich phase, as cited in the literature. ${ }^{22} \mathrm{~F}$ or the 60/40 P46/PC blends, the low $\mathrm{T}_{g}$ belonged to $\mathrm{P} 46$ and the high $\mathrm{T}_{\mathrm{g}}$ was due to $\mathrm{PC}$, as illustrated in Figure 2. In Figure 2, only the portion of the DSC curve containing glass transition temperatures of P46 and PC was displayed. The two Tg's were separated by 56 deg after the blend was annealed at 


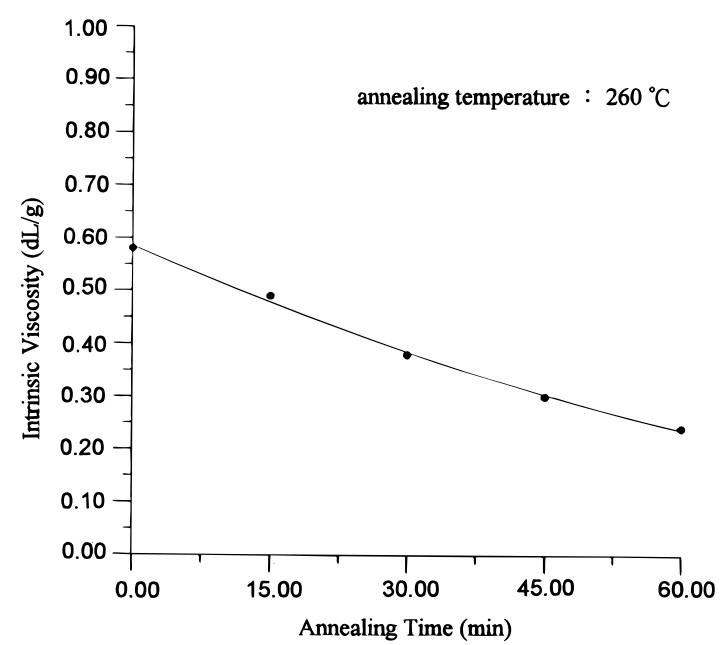

Figure 3. Intrinsic viscosity of the $60 / 40$ P46/PC blend after being annealed at $260{ }^{\circ} \mathrm{C}$ for different times.

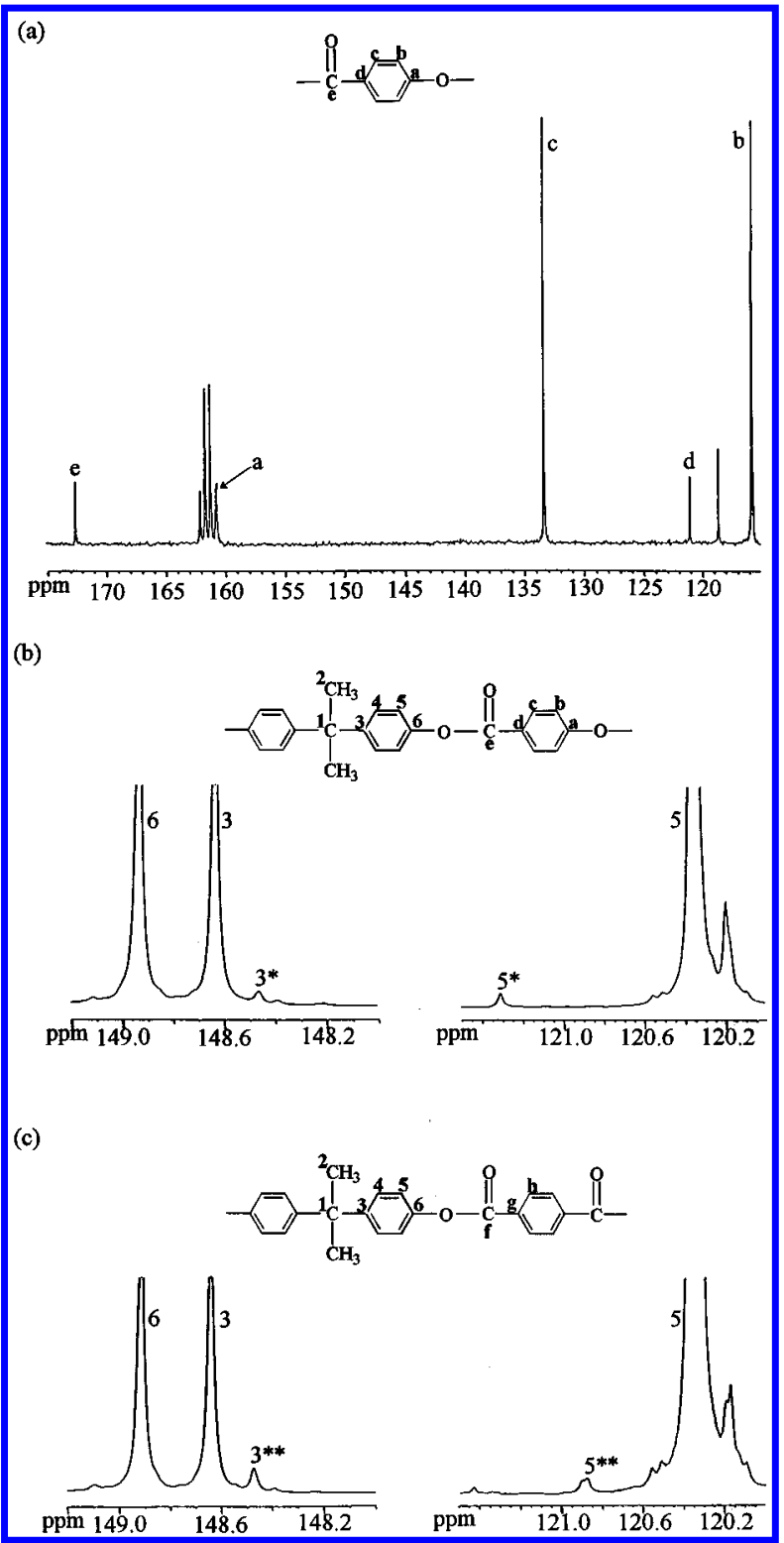

Figure 4. ${ }^{13} \mathrm{C} 600 \mathrm{MHz}$ NMR spectra of (a) hydroxybenzoic acid (HBA), (b) the soluble fraction of PC/HBA (80/20) mixed at $220^{\circ} \mathrm{C}$ for $30 \mathrm{~min}$ (3* and $5^{*}$ were new peaks), (c) the soluble fraction of PC/TA (80/20) mixed at $300^{\circ} \mathrm{C}$ for $30 \mathrm{~min}\left(3^{* *}\right.$ and $5 * *$ were new peaks).

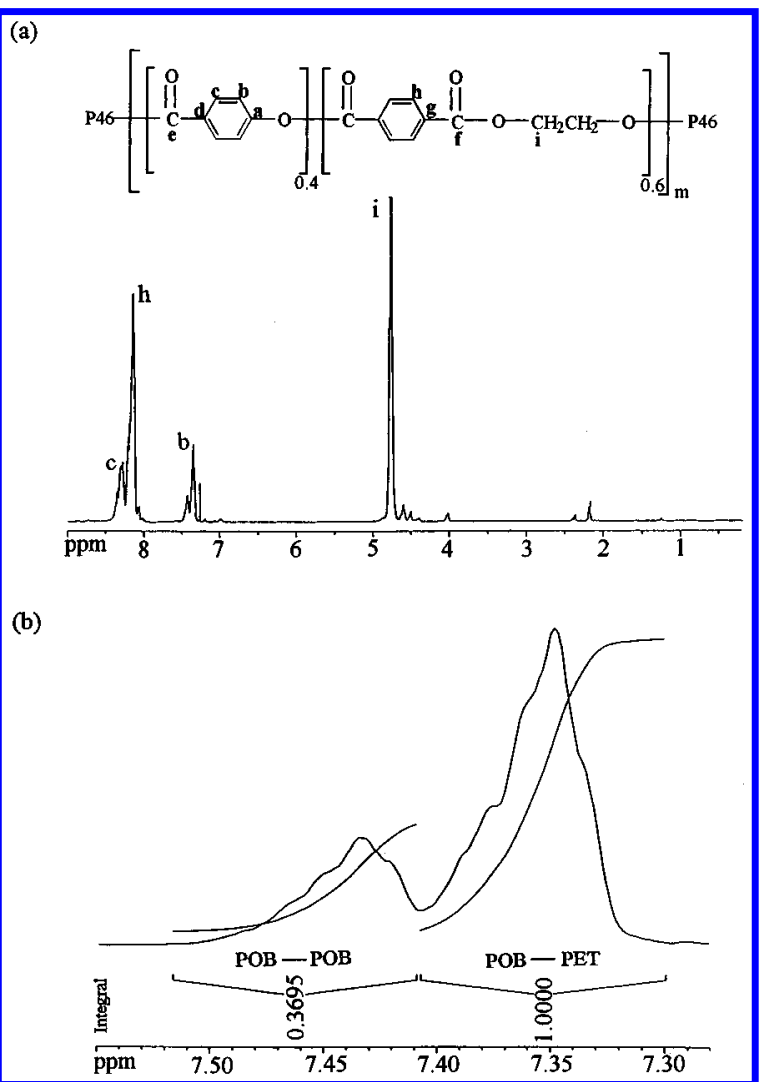

Figure 5. (a) Proton $600 \mathrm{MHz} N M R$ spectrum of the $\mathrm{P} 46$ copolymer. (b) Peak integrals of $\mathrm{POB}-\mathrm{POB}$ and $\mathrm{POB}-\mathrm{PET}$ peaks.

$260{ }^{\circ} \mathrm{C}$ for $15 \mathrm{~min}$. As the annealing time increases, the two $\mathrm{T}_{\mathrm{g}}$ 's converged on each other. There was only one $\mathrm{T}_{\mathrm{g}}$ appearing at $109.5^{\circ} \mathrm{C}$ after $60 \mathrm{~min}$ of annealing at $260^{\circ} \mathrm{C}$. Near the single $\mathrm{T}_{\mathrm{g}}$, there appears to remain some small structure at $90-100{ }^{\circ} \mathrm{C}$ that was possibly due to the residual crystallization of traces of PET microdomain in P46 after al lowing the blend to crystallize at $170{ }^{\circ} \mathrm{C}$ for $10 \mathrm{~min}$, as described in the Experimental Section, whereas the small structure at 120 $130{ }^{\circ} \mathrm{C}$ is likely due to traces of PC microdomain since the onset point of the $\mathrm{PC}$ glass transition is $125^{\circ} \mathrm{C}$ (see Figure 1). Despite these two small structures, the single $\mathrm{T}_{\mathrm{g}}$ behavior exhibited by the blend indicated an almost complete miscibility between P46 and PC. This miscibility result is similar to the homogenization results in the PET/PC blend obtained with solid state NMR. ${ }^{15}$ In a parallel measurement, the intrinsic viscosity of the $60 / 40$ P46/PC blends decreased with increasing annealing time at $260{ }^{\circ} \mathrm{C}$, as illustrated in Figure 3. After 60 min of annealing, the intrinsic viscosity of the blend dropped to almost half its original value. The reduction of the intrinsic viscosity of the annealed blend was apparently caused by a reaction between the polymers. The reaction possibilities included partial hydrolysis ${ }^{10}$ of the copolyester P46, decarboxylation in $\mathrm{PC}^{23}$ and ester-ester interchange ${ }^{12}$ in P46 and PC. Since the annealing of the blend was carried out in a vacuum tube at $260^{\circ} \mathrm{C}$ under $10^{-1} \mathrm{Torr}$, the possibility of hydrolysis of P46 was reduced to a minimum. The decarboxylation resulting from acidolyis of PC by the end group of P46 existed but was not a dominant factor because the concentration of the end group of P46 was not particuIarly high. It seemed that the ester-ester interchange between the two polymers only averaged the molecular sizes. In fact, the transesterification would also cause P46 to lose its rigid rod nature, and therefore reduced 


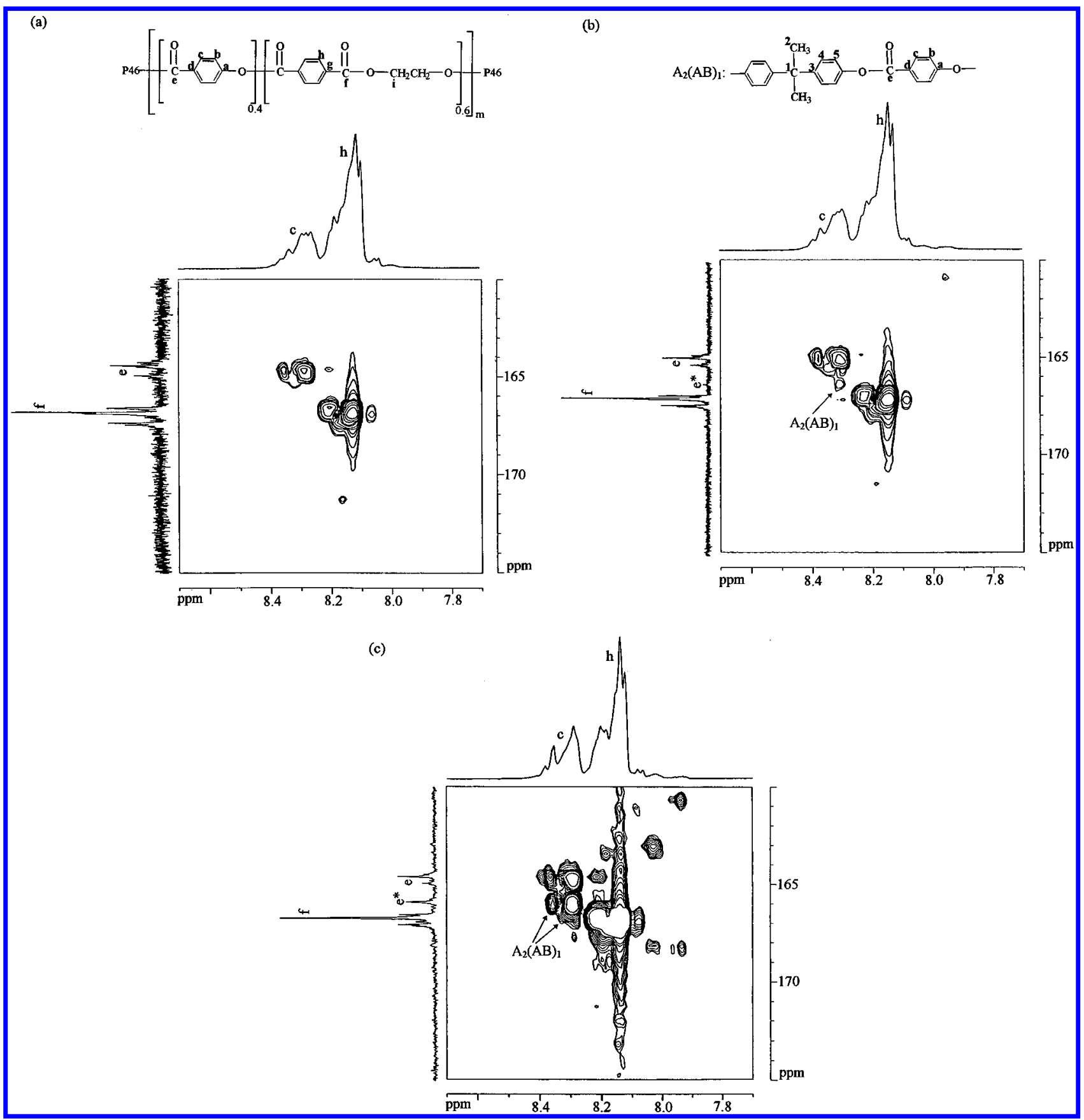

Figure 6. ${ }^{1} \mathrm{H}-{ }^{13} \mathrm{C} 600 \mathrm{MHz}$ NMR spectra of the 60/40 P46/PC blend: (a) freshly prepared; (b) after being anneal ed at $260{ }^{\circ} \mathrm{C}$ for $30 \mathrm{~min}$; (c) after being annealed at $260{ }^{\circ} \mathrm{C}$ for $60 \mathrm{~min}$.

Table 2. Chemical Shifts of Aromatic ${ }^{13} \mathrm{C}$ in Blends of HBA/PC and TA/PC

compound or polymer

hydroxybenzoic acid (HBA)

soluble fraction of reacted HBA/PC (20/80) at $220^{\circ} \mathrm{C}$ for $30 \mathrm{~min}$ soluble fraction of reacted Terephthalic acid/PC (20/80) at $300{ }^{\circ} \mathrm{C}$ for $30 \mathrm{~min}$

its intrinsic viscosity (IV) dependency on molecular weight. This is clarified by the Mark-Kuhn-Houwink-Sakurada equation IV $=\mathrm{KM}^{\alpha}$, where $\mathrm{K}$ is a constant and $\mathrm{M}$ is the molecular weight. For flexible chain polymers the $\alpha$ value is between 0.5 and 1 , and the $\alpha$ value may exceed unity in the case of rigid-rod polymers. ${ }^{24}$ Hence, the crucial reduction in the intrinsic viscosity of the annealed blend most likely came from some decarboxylation and transesterification. From the single $\mathrm{T}_{\mathrm{g}}$ and a large decrease in intrinsic viscosity, one deduced that the ester exchange reaction had taken place between P46 and PC. The actual confirmation of

$\begin{array}{lllll}160.5\left(\mathrm{C}_{\mathrm{a}}\right) & 115.6\left(\mathrm{C}_{\mathrm{b}}\right) & 121.0\left(\mathrm{C}_{\mathrm{c}}\right) & 133.3\left(\mathrm{C}_{\mathrm{d}}\right) & 172.5\left(\mathrm{C}_{\mathrm{e}}\right) \\ 148.6\left(\mathrm{C}_{3}\right) & 148.47\left(\mathrm{C}_{3^{*}}\right) & 120.34\left(\mathrm{C}_{5}\right) & 121.3\left(\mathrm{C}_{5^{*}}\right) & 148.92\left(\mathrm{C}_{6}\right) \\ 148.6\left(\mathrm{C}_{3}\right) & 148.46\left(\mathrm{C}_{3^{*}}\right) & 120.34\left(\mathrm{C}_{5}\right) & 120.88\left(\mathrm{C}_{5^{*}}\right) & 148.92\left(\mathrm{C}_{6}\right)\end{array}$

the chemical structure change in these polymers resulting from ester exchange has been carried out with NMR analysis. In the model compound study, the aromatic regions of the ${ }^{13} \mathrm{C}$ NMR spectra of hydroxybenzoic acid (HBA), PC/HBA (80/20), and PC/terephthalic acid (TA) $(80 / 20)$ are shown in Figure $4 a-c$, respectively. The NMR spectrum of HBA in Figure $4 a$ was used for comparison later. The two resultant peaks from diad Bisphenol $A$-oxybenzoate $\left(A_{2}(A B)_{1}\right)$ were identified as $3^{*}$ and $5^{*}$, as indicated in Figure $4 \mathrm{~b}$, and their ${ }^{13} \mathrm{C}$ chemical shifts were 148.47 and 121.30 ppm, respectively, whereas for the TA/PC case, the ${ }^{13} \mathrm{C}$ chemical 


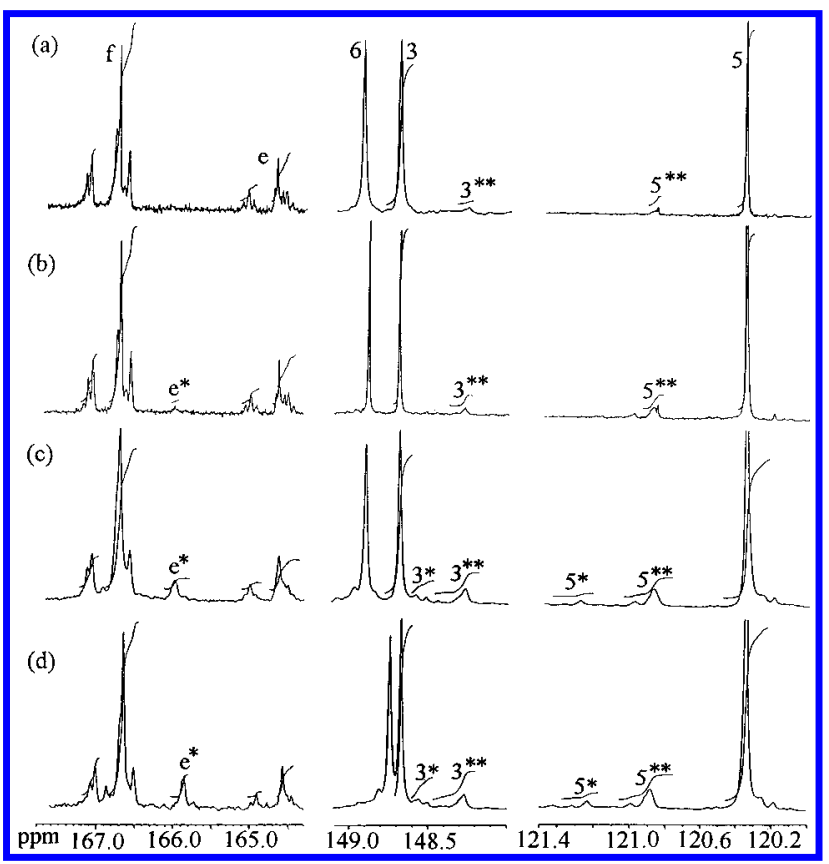

Figure 7. ${ }^{13} \mathrm{C} 600 \mathrm{MHz}$ NMR spectra of $60 / 40 \mathrm{P} 46 / \mathrm{PC}$ blends after being annealed at $260{ }^{\circ} \mathrm{C}$ for (a) $15 \mathrm{~min}$, (b) $30 \mathrm{~min}$, (c) $45 \mathrm{~min}$, and (d) $60 \mathrm{~min}$.

shifts for the new resultant peaks were $148.46 \mathrm{ppm}\left(3^{* *}\right)$ and $120.88 \mathrm{ppm}\left(5^{* *}\right)$, as shown in Figure 4c. This indicated formation of Bisphenol $A$-terephthalate $\left(A_{2} B_{1}\right)$. The detailed chemical shifts in the NMR spectra of these model compounds are listed in Table 2. Probably due to the fact that the concentration of oxybenzoate is low, the peaks in the ester region of the ${ }^{13} \mathrm{C}$ NMR spectra were much weaker than can be observed. The structure change caused by the transesterification in the ester region of the blend was directly analyzed with twodimensional ${ }^{1} \mathrm{H}-{ }^{13} \mathrm{C}$ HMBC NMR spectra. Since the most change occurred in the aromatic and ester region of the P46/PC blend, we focused on these two regions of the NMR spectra. Before going on to the blends, we analyzed P46. The ${ }^{1} \mathrm{H}$ NMR spectrum of synthesized $\mathrm{P} 46$ is shown in Figure 5a. The fraction of the POBPOB peak area in both the POB-POB and PET-PET peak area is 0.269 , as displayed in Figure $5 \mathrm{~b}$. On the basis of a probability calculation, 25 a fully random copolymer of P46 should have a value of 0.25 . There fore, P46 is very close to a random copolymer. The partial aromatic and carbonyl regions of the ${ }^{1} \mathrm{H}-{ }^{13} \mathrm{C}$ NMR spectra of the 60/40 P46/PC blend are shown in Figure 6. In Figure 6a, the resonance peaks of the freshly prepared 60/40 P46/PC blend indicated that the blend is a mechanical mixing of two polymers. When the $60 / 40 \mathrm{P} 46 / \mathrm{PC}$ blend was annealed at $260{ }^{\circ} \mathrm{C}$ for 30 min, a small new peak appeared at 8.3-166 ppm in the ${ }^{1} \mathrm{H}-{ }^{13} \mathrm{C}$ spectra of the blend, as presented in Figure $6 \mathrm{~b}$. Then, two full new cross peaks located at 8.3-166 ppm and $8.37-166 \mathrm{ppm}$ showed up in the NMR spectra of the blend after $60 \mathrm{~min}$ of annealing, as shown in Figure 6c. From reading the relative position of ${ }^{1} \mathrm{H}$ to ${ }^{13} \mathrm{C}$, we knew it was the aromatic $\mathrm{H}_{\mathrm{c}}$ in the $\mathrm{POB}$ segment attached to the carbonyl $\mathrm{C}_{\mathrm{e}}$ in the POB segment. Hence, we deduced that these new peaks in the ester region were caused by the new structure $A_{2}(A B)_{1}$ or Bisphenol $A$ attached to oxybenzoate. To quantify the chemical structures corresponding to these resonance peaks, a one-dimensional ${ }^{13} \mathrm{C}$ NMR spectral analysis of the annealed blends was carried out and presented in Figure 7. After the blend was annealed for $15 \mathrm{~min}$,

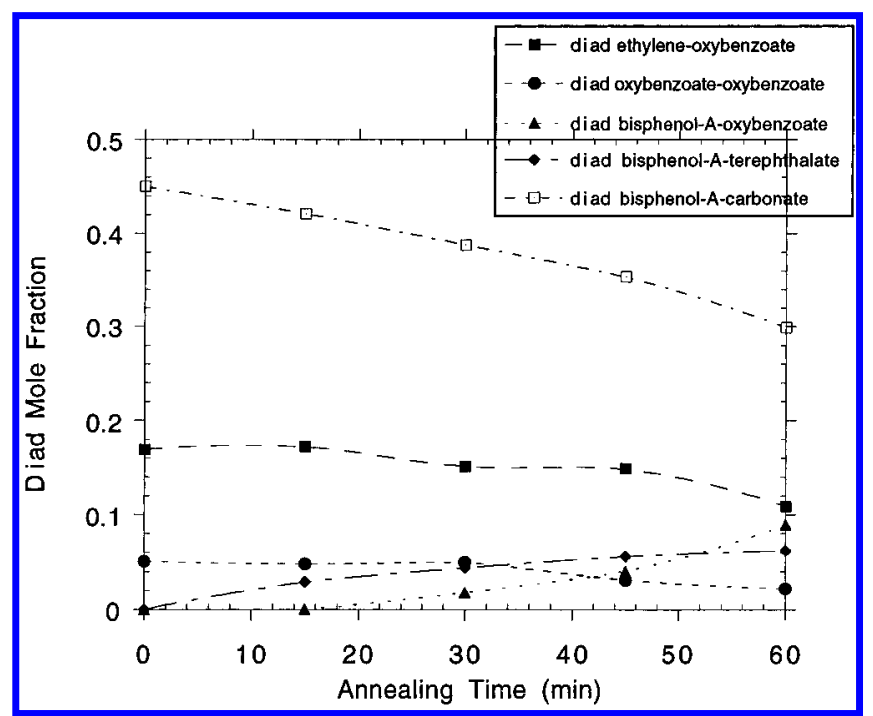

Figure 8. Transient diad mole fraction in 60/40 P46/PC blends annealed at $260{ }^{\circ} \mathrm{C}$ obtained from nuclear magnetic resonance analysis.

there were two new peaks $3^{* *}$ and $5^{* *}$ appearing at 120.9 and 148.38 ppm, respectively as shown in Figure 7a. These two new peaks represented the structure Bisphenol $A$-terephthalate $\left(A_{2} B_{1}\right)$, judging from the model compound study. When the annealing time increased to $30 \mathrm{~min}$, an additional new peak $\mathrm{e}^{*}$ showed up at $165.9 \mathrm{ppm}$ and was identified as Bisphenol $A$-oxybenzoate $\left(A_{2}(A B)_{1}\right)$, as shown in Figure $7 b$. Although the new peaks $3^{*}$ and $5^{*}$ in the aromatic region of the NMR spectra of the blend appeared after $45 \mathrm{~min}$ of annealing, we still recognized the e* peak as the first appearing evidence of Bisphenol A-oxybenzoate. For calculating the transient mole fraction of diads, the initial mole fractions of Bisphenol $A\left(A_{2}\right)$, ethylene $\left(A_{1}\right)$, and oxybenzoate $\left((A B)_{1}\right)$ in this 60/40 P 46/PC blend were determined from eqs $1 A, 1 B$, and 2 . The values of $F A_{2}$, $F A_{1}$, and $F(A B)_{1}$ obtained were $0.45,0.33$, and 0.22 , respectively. The diad existing probabilities were proportional to the integrals under the resonance peaks. Taking the integral values under the resonance peaks in Figure 7 and substituting them into eqs 13-16, the transient mole fraction of diads in the 60/40 P46/PC blend is obtained and presented in Figure 8. In Figure 8 , the formation of the diad Bisphenol A-oxybenzoate $\left(A_{2}(A B)_{1}\right)$ increased markedly and exceeded that of the diad Bisphenol $A$-terephthalate $\left(A_{2} B_{1}\right)$ after 55 min of annealing time. The increase of the diad Bisphenol A-terephthalate $\left(A_{2} B_{1}\right)$ became saturated at 0.062 mole fraction after $60 \mathrm{~min}$ of annealing. The loss of diad mole fractions of ethylene- oxybenzoate $\left(A_{1}(A B)_{1}\right)$, Bisphenol $A$-carbonate $\left(A_{2} B_{2}\right)$, and oxybenzoate-oxybenzoate $\left((A B)_{1}(A B)_{1}\right)$ were $36 \%$, 33.5\%, and $57 \%$, respectively, after $60 \mathrm{~min}$ of annealing at $260^{\circ} \mathrm{C}$. The transient mole fraction of diad $A_{2} B_{2}$ is determined by subtracting $F A_{2} B_{1}$ and $F A_{2}(A B)_{1}$ from the initial $F A_{2} B_{2}$. This calculation is at $1 \mathrm{~h}$ of annealing time when the annealed blend was miscible but not yet purely randomized. For a purely randomized blend, the loss of diad mole fraction $\mathrm{A}_{2} \mathrm{~B}_{2}$ would be $84.7 \%$ based upon the initial P46 and PC composition in the blend. The large loss of the diad oxybenzoate-oxybenzoate $\left((A B)_{1}(A B)_{1}\right)$ after 60 min of annealing resulted in the disappearance of the liquid crystalline phase. This certainly caused an improvement in the miscibility of the originally immiscible 60/ $40 \mathrm{P} 46 / \mathrm{PC}$ blends (two distinctive $\mathrm{T}_{\mathrm{g}}$ 's). This result corresponded very well to the complete miscibility 
behavior (a single glass transition temperature) in the annealed 60/40 P46/PC blend obtained by the DSC measurement.

\section{Conclusion}

From the diad analysis and the NMR results, we concluded that ester-ester interchange in the blends of random liquid crystalline copolyester P46 and polycarbonate took place within 15 min when the blend was annealed at $260{ }^{\circ} \mathrm{C}$ under vacuum. In the annealed blend, the Bisphenol A unit in polycarbonate reacted first with the terephthalate unit and then with the oxybenzoate unit in copoly(oxybenzoate-p-terephthalate). As the reaction in the blend continued for about $1 \mathrm{~h}$, the production of diad Bisphenol A-oxybenzoate sped up and exceeded that of diad Bisphenol A-terephthalate. This caused a large loss (57\%) of diad oxybenzoate-oxybenzoate and led to the disappearance of the liquid crystalline phase in the annealed blend. In sharp contrast to the originally immiscible blend of PC and P46 (two distinctive glass transition temperatures), the large loss in the liquid crystalline diad resulted in complete miscibility (a single glass transition temperature) in the annealed blend, as evidenced by the differential scanning calorimetry measurement.

Acknowledgment. The authors appreciate the financial support provided by the National Science Council through Project NSC85-2216-E-009-005. Additionally, we thank Ms. Chu-Lan Peng for the help with nuclear magnetic resonance experiments.

\section{References and Notes}

(1) Kiss, G. Polym. Enq. Sci. 1987, 27, 410.
(2) Kolhi, A.; Chung, N.; Weiss, R. A. Polym. Eng. Sci. 1989, 29, 573.

(3) Brostow, W. Polymer 1990, 31, 979.

(4) Wei, K. H.; Kiss, G. Polym. Enq. Sci. 1996, 36, 713.

(5) Wei, K. H.; Hwang, W. J .; Tyan, H. L. Polymer 1996, 37, 2087.

(6) Tang, P.; Reimer, J . A.; Denn, M. M. Macromolecules 1993 26, 4269.

(7) Bafna, S. S.; Sun, T.; de Souza, J . P.; Baird, D. G. Polymer 1995, 36, 259.

(8) Economy, J .; Goranov, K. in Advances in Polymer Science Hergenrother, P. M., Ed.; Springer-Verlag: Berlin, 1994.

(9) Kotliar, A. M. L. Polym. Sci., Macromol. Rev. 1981, 16, 367.

(10) Pilati, F.; Marianucci, E.; Berti, C. J . L. Appl. Polym. Sci. 1985, 30, 1267.

(11) Kimura, M.; Porter, R. S. L. Polym. Sci., Polym. Phys. Ed. 1983, $21,367$.

(12) Su, K. F.; Wei, K. H. I. Appl. Polym. Sci. 1995, 56, 79.

(13) Laivins, G. V. Macromolecules 1989, 22, 3974.

(14) Godard, P.; Dekoninck, J . M.; Devlesaver, V.; Devaux, J . L. Polym. Sci.: Part A: Polym. Chem. 1986, 24, 3301.

(15) Henrichs, P. M.; Tribone J .; Massa, D. J .; Hewitt, J. M. Macromolecules 1988, 21, 1282.

(16) Wei, K. H.; Jang, C. J .; Ho, J . C. Polymer, in press.

(17) Yamadera, R.; Murano, M. J . L. Polym. Sci., Polym. Chem. Ed. 1967, 5, 2259.

(18) Devaux, J .; Godard, P.; Mercier, P. L. Polym. Sci., Polym. Phys. Ed. 1982, 20, 1875.

(19) Kollodge, J. S.; Porter, R. S. Macromolecules 1995, 28, 4106.

(20) Espinosa, E.; Fernandez-Berridi, M. J .; Inaki, M.; Valero, M. Polymer 1994, 34, 382.

(21) Jackson, J . R.; Kuhfuss, H. F. L. Polym. Sci., Polym. Chem. Ed. 1976, 14, 2043.

(22) Porter, R. S.; Wang, L. H. Polymer, 1992, 33, 2019.

(23) Schilling, F. C.; Ringo, W. M., J r.; Sloane, N.J . A.; Bovey, F. A. Macromolecules 1981, 14, 532.

(24) Vinogradov, C. V.; Malkin, A. Y. Rheology of Polymers; Springer-Verlag: New York, 1980.

(25) Vollmert, B. Polymer Chemistry; Springer-Verlag: New York, 1973.

MA9615260 